\title{
ARTICULACIÓN DE LA EDUCACIÓN TÉCNICO PROFESIONAL: UNA CONTRIBUCIÓN PARA SU COMPRENSIÓN Y CONSIDERACIÓN DESDE LA POLÍTICA PÚBLICA ${ }^{1}$
}

\author{
María Paola Sevilla ${ }^{2}$, Mauricio Farías $^{3}$, Marcela Weintraub ${ }^{4}$
}

\begin{abstract}
RESUMEN
En una era caracterizada por los constantes cambios tecnológicos y la demanda de competencias técnicas de alto nivel, la Educación Técnico Profesional requiere proyectarse más allá de los programas escolares y asegurar oportunidades claras de aprendizaje posterior. El presente artículo pretende contribuir a ampliar el conocimiento respecto del desafío de la articulación en este ámbito. Para ello, junto con realizar una revisión de experiencias internacionales y un estudio de casos en el contexto chileno, ensaya una definición de articulación coherente con sus propósitos. Los hallazgos dan cuenta de que los países que han avanzado en conectar su oferta formativa técnica profesional entre sus distintos niveles, han declarado explícitamente que la articulación es una meta prioritaria y realizan acciones múltiples para alcanzarla. En cambio, Chile carece de una política nacional en la materia y de una normativa que facilite el progreso educativo eficiente de los grupos más vulnerables que cursan estudios técnicos. Los avances en articulación son incipientes, en general, restringidos al ámbito curricular, lo que en la práctica se traduce en acuerdos institucionales uno a uno, que para las instituciones de educación superior resultan en mecanismos de atracción de matrícula vocacionalmente cautiva. El estudio sugiere la toma urgente de medidas para avanzar hacia un sistema educativo que facilite y promueva la acumulación de capital humano de tipo técnico y, por esa vía, que favorezca el crecimiento económico y la equidad de oportunidades.

Palabras clave: articulación, educación técnico profesional secundaria, educación técnico profesional postsecundaria.
\end{abstract}

\section{ARTICULATION OF VOCATIONAL TECHNICAL EDUCATION: A CONTRIBUTION FOR ITS COMPREHENSION AND CONSIDERATION IN PUBLIC POLICY}

ABSTRACT

In an era characterized by constant technological changes and a demand for high-level technical skills, Secondary Vocational Technical Education needs to project itself far beyond the secondary curriculum and provide clear opportunities for further learning. This article aims to contribute to a broader knowledge regarding the challenge of articulation in this field. To this end, along with a revision of international experience and case studies of the Chilean context, the article aims to provide a definition of articulation coherent with the purposes of vocational education. The findings reveal that the countries that have made progress in connecting the distinct levels of vocational technical educational offerings, have explicitly declared that articulation is a prioritized goal and have carried out multiple actions in order to achieve it. Chile, however, lacks a national policy agenda for this field and standards that would facilitate an efficient education trajectory for the most vulnerable students that pursue technical careers. The advances in articulation are in their early stages, and generally limited to curriculum, which in practice translates into unique institutional agreements, that function for institutions of higher learning as a mechanism to target the predetermined market of vocational students. The study suggests the urgency of taking measures to advance towards an education system that would facilitate and promote the accumulation of technically skilled human capital and that would thus favor economic growth and greater equality of opportunity.

Keywords: articulation, secondary vocational technical education, post-secondary vocational technical education

1 Artículo apoyado por la Convocatoria de apoyo a la investigación en educación del Consejo Nacional de Educación. Adicionalmente, el autor Mauricio Farías, al momento de elaborar este documento, contaba con financiamiento del programa de Inserción de Capital Humano en la Industria, proyecto "Más capital humano para Chile" de Conicyt.

2 Doctorado en Educación, Universidad Alberto Hurtado y Universidad Diego Portales. Facultad de Educación, Universidad Diego Portales, Santiago, Chile. Contacto: paola. sevilla@gmail.com

3 Fundación Chile, Santiago, Chile. Contacto: mauricio_farias@yahoo.com.

4 Investigadora independiente, Santiago, Chile. Contacto: marcelawein@gmail.com 
84 ARTICULACIÓN DE LA EDUCACIÓN TÉCNICO PROFESIONAL: UNA CONTRIBUCIÓN PARA SU COMPRENSIÓN Y CONSIDERACIÓN DESDE LA POLÍTICA PÚBLICA - M. Sevilla, M. Farías y M. Weintraub

\section{Introducción}

La presente década es testigo de un renovado interés por la Educación Técnico Profesional (ETP). Después de un largo periodo de desatención y marginamiento de los debates de política educativa, este tipo de formación está siendo nuevamente promovido por los organismos internacionales y los gobiernos nacionales (OECD, 2010; Unesco, 2012; Cedefop, 2014). En este resurgimiento de la ETP, el desafío está puesto en el fortalecimiento de sus competencias transversales y en su capacidad de ofrecer programas pertinentes y articulados con niveles superiores de formación, como parte de una estrategia de promoción del aprendizaje a lo largo de la vida que permita enfrentar los cambios tecnológicos y el requerimiento de competencias técnicas de alto nivel (Unesco, 2012).

Se trata de una nueva concepción de la ETP que la aleja definitivamente de la imagen de una formación terminal que prepara para un puesto específico de trabajo y que la convierte en una opción que, a través de la creación de itinerarios formativos desde el nivel secundario hacia el postsecundario, fomenta el acceso y permanencia en el sistema educativo de poblaciones desfavorecidas (Stipsnovic, Lewis \& Stringfield, 2012). Sin embargo, para transformar a la ETP en un mecanismo efectivo de promoción de igualdad de oportunidades muchas naciones, entre ellas Chile, requieren reformar esta educación, conectando sus distintos niveles y fortaleciendo su formación general, entre otros aspectos (OECD, 2009).

En Chile, la Educación Media Técnico Profesional (EMTP) está legalmente abierta a la educación superior y promete a los jóvenes y las familias que la eligen, una formación integral en el ámbito de una especialidad que facilite su inserción laboral, así como también la posibilidad de continuación de estudios. No obstante este segundo propósito, en la práctica, no se sustenta en la enseñanza de contenidos académicos ni en la existencia de conexiones formales con la Educación Superior Técnico Profesional (ESTP). Como norma general, los programas de estudio técnicos entre los niveles secundario y terciario no están alineados, lo que lleva muchas veces a sus egresados a repetir contenidos ya cursados, sin la posibilidad de que sus aprendizajes 
previos sean reconocidos. Para Sepúlveda (2011), esta falta de conexión de la EMTP con la ESTP es uno de los síntomas de la ambigüedad estratégica en la que se encuentra esta modalidad formativa.

Diversos informes han subrayado insistentemente el desafío de la articulación como uno de los más urgentes para la ETP chilena (OECD, 2004; OECD, 2009; Mineduc, 2006; Consejo Asesor Presidencial, 2006; Comisión Externa Formación Técnica, 2009; Mineduc, 2011). Pese a ello, esta temática no ha sido abordada desde la investigación educativa con la profundidad y extensión requerida. La escasa literatura nacional en la materia ha puesto el foco principalmente en la articulación al interior de la educación superior (Cáceres, 2007; Gaete y Morales, 2011). El presente artículo, pretende contribuir a ampliar el conocimiento respecto del desafío de la articulación en el ámbito de la educación técnica secundaria y postsecundaria. Para ello realiza una propuesta de definición de articulación que traspasa la dimensión curricular y que incluye otros elementos que dan soporte no solo al acceso, sino también al éxito en la educación superior. A la luz de esta definición se realiza una revisión de experiencias internacionales y un análisis de casos de instituciones que han avanzado en la vinculación de la ETP en sus distintos niveles. El fin último es contar con antecedentes relevantes que permitan generar orientaciones de política pública en materia de articulación.

A nuestro juicio, el discurso de la EMTP como modalidad no terminal y válida para la continuidad de estudios solo se puede sostener en la medida en que este tipo de educación fortalezca sus contenidos académicos y se articule con la ESTP. Países como Estados Unidos han sustentado el mandato a sus programas técnicos escolares de proyectar a sus estudiantes al nivel postsecundario, en acciones legislativas que han impulsado modelos de articulación sostenidamente en el tiempo, basados en la alineación de los contenidos técnicos y el énfasis en el rigor académico. Otros países como Australia cuentan con estructuras formales provistas por marcos nacionales de cualificaciones que articulan la educación técnica en sus distintos niveles, fomentando el aprendizaje permanente. Finalmente, países con sistemas de ETP secundaria fuertes como Alemania, China y España cuentan con instituciones que fusionan esta educación con 
la de nivel postsecundario (U.S. Department of Education, 2012; NCVER, 2002; Musset \& Field, 2013).

En nuestro país, los principales esfuerzos en materia de articulación se realizaron en el marco del Programa Chile Califica, que a través de la línea de Redes de Articulación de la Formación Técnica, propició la asociación de instituciones formativas y productivas para la generación de ofertas formativas articuladas y pertinentes. Entre los años 2003 y 2009 se conformaron 25 redes para implementar el mandato, sin embargo, no se logró instalar los itinerarios de formación técnica entre los niveles secundario y superior (DIPRES, 2009). La falta de incentivos para la colaboración mutua entre las instituciones que conformaban una misma red y el exclusivo foco puesto en lo curricular se identifican como las limitantes de esta estrategia (Castro y Orellana, 2010).

Este artículo se organiza en cuatro secciones. La primera de ellas contiene el marco de referencia bajo el cual se aborda el fenómeno de articulación en la investigación en lo relativo a su alcance conceptual, beneficios, limitantes y facilitadores. La descripción de las experiencias en materia de articulación para un conjunto de países, entre ellos Estados Unidos, Australia, China, España y Colombia, está contenida en la segunda sección. Por su parte, la tercera sección presenta el estudio de casos de instituciones que han avanzado en vincular la EMTP con la ESTP. Finalmente, la discusión y el análisis transversal de los hallazgos, junto con las principales conclusiones y orientaciones de políticas se encuentran en la última sección.

\section{Marco de referencia}

\subsection{Alcance del concepto de articulación y propuesta de definición}

En el campo de la educación, el término "articulación" tiene diferentes acepciones y propósitos según los niveles o sectores que involucre. Se trata de un concepto no normalizado por la literatura que incluso en un mismo contexto de aplicación como la ETP, puede ser interpretado de variadas formas por los actores locales y diseñadores de política. 
Una revisión a los trabajos que han abordado la problemática de la articulación en el ámbito internacional da cuenta de, al menos, dos aspectos que resultan relevantes considerar en el proceso de clarificación y aproximación conceptual a este término. El primero se refiere a la pertinencia de delimitar el alcance del concepto de articulación en el plano curricular. El segundo da cuenta de la necesidad de definir el término de una manera amplia que sobrepase la dimensión curricular, a fin de considerar todos los elementos que condicionan sus fines deseados.

La Figura 1 da cuenta de los distintos mecanismos que dan soporte al tránsito de estudiantes entre los niveles secundario y postsecundario de la ETP con convalidación de cursos o asignaturas ${ }^{5}$. Se incluyen los exámenes de conocimientos relevantes, las convalidaciones directas que emergen de procesos institucionales de "equivalencia curricular" entre los programas de estudio de ambos niveles y las convalidaciones caso a caso que acontecen cuando los alumnos negocian de forma individual el reconocimiento de sus cursos. Un cuarto mecanismo que se incluye, especialmente efectivo para evitar la duplicación de contenidos y ofrecer una formación coherente y secuencial, es la elaboración coordinada de planes de estudios o "convergencia curricular" entre niveles. Algunos autores reservan el término de articulación para referirse exclusivamente a los arreglos institucionales o estructuras bajo las cuales se gesta este proceso de diseño o ajuste curricular (Robertson-Smith, 1990; PhillipsKA, 2006). Otros, en cambio, denominan articulación a los acuerdos institucionales que permiten a los estudiantes completar un programa de estudios convalidando directamente sus asignaturas o usando créditos acumulados en otro programa (Carmichael, Hall $\&$ O' Meara, 2007). Finalmente, hay quienes como Clark (1998) que emplean de una manera más amplia el término y lo utilizan para referirse a todo mecanismo que favorezca el tránsito fluido de estudiantes de un nivel a otro, sin explicitar si esto es con o sin convalidación de cursos.

5 En contextos con marcos de cualificaciones o sistemas de créditos transferibles instalados, se habla de admisión con y sin créditos (PhillipsKA, 2006). 
88 ARTICULACIÓN DE LA EDUCACIÓN TÉCNICO PROFESIONAL: UNA CONTRIBUCIÓN PARA SU COMPRENSIÓN Y CONSIDERACIÓN DESDE LA POLÍTICA PÚBLICA - M. Sevilla, M. Farías y M. Weintraub

Figura 1: Mecanismos para el tránsito entre niveles de la ETP con convalidación de asignaturas

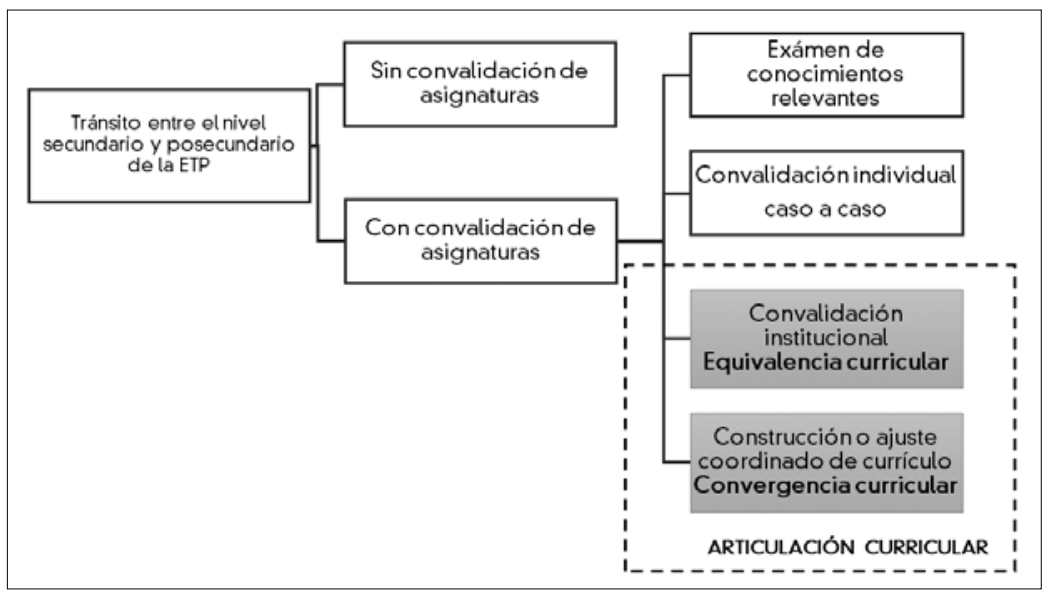

En general, los procesos de examinación de conocimientos relevantes y convalidaciones de asignaturas caso a caso son mecanismos que se encuentran bien normados en las instituciones proveedoras de ETP. Sin embargo, para Curtis (2009) los estudiantes no siempre están conscientes de su existencia y muchas veces transitan de un nivel a otro sin reconocer sus aprendizajes previos. Asimismo, para PhillipsKA (2006) se trata de procesos que resultan engorrosos administrativamente, ocupando muchos recursos de gestión, además de dejar en una situación de incertidumbre al estudiante quien solo conoce los resultados de la convalidación después de postular a la institución. Por su parte, la equivalencia y convergencia curricular evitan a los estudiantes duplicar estudios previos a través de acuerdos institucionales que potencialmente permitirían avanzar en otros ámbitos. Ambos procesos serán referidos en este estudio bajo el término de "articulación curricular".

En relación con la necesidad de definir el término de articulación de una manera más holística, autores como Shaw (2012) llaman a incluir otros elementos en su definición. Entre ellos, la existencia de una institucionalidad o estructura organizacional que permita cerrar la brecha entre los modelos de provisión de educación técnica de distintos niveles y la presencia del rigor académico en los programas 
de educación técnica escolar. Por su parte, Clark (1998) invita a definir la articulación también como actitud y dar cuenta de la disposición de los docentes de distintos sectores para trabajar conjuntamente a favor del desarrollo del estudiante, trascendiendo los intereses individuales e institucionales. Incluye de ese modo elementos culturales en su acercamiento conceptual al fenómeno.

En el ámbito nacional, Gaete y Morales (2011) avanzan en acotar la definición de articulación en el plano curricular cuando refieren bajo este término al diseño conjunto de planes de estudio de un mismo o de diferente nivel formativo, a fin de lograr una sintonización eficaz y coherente del currículo. Sin embargo, no consideran elementos adyacentes que condicionan los propósitos de la articulación. Otras definiciones de articulación como la de Cáceres (2007), que si bien incluyen bajo este término consideraciones de financiamiento y regulación que acompañan la coordinación curricular de las instituciones, lo hacen para enfatizar la libertad y autonomía de las instituciones de educación superior en este proceso.

Para fines de esta investigación se concibe el término de articulación, como la conjunción de elementos curriculares, pedagógicos, institucionales y culturales que propician el tránsito eficiente y exitoso hacia la educación superior de estudiantes egresados de programas técnicos escolares. Los elementos curriculares se refieren a los procesos de equivalencia o convergencia curricular gestados en el marco de acuerdos entre instituciones formadoras; los elementos pedagógicos corresponden a la preparación previa de los estudiantes para la educación superior, tanto en términos académicos como de orientación vocacional, y a su posterior soporte y acompañamiento en dicha etapa. Este aspecto no solo pone el foco en el acceso -siempre presente en las definiciones de articulación-, sino también apunta al éxito en la educación superior; los elementos institucionales, por su parte, corresponden a la existencia de estructuras y formas, a través de incentivos y aspectos reguladores desde el Estado, para el trabajo colaborativo entre las instituciones escolares y de educación superior en los planos curriculares y pedagógicos; finalmente, los elementos culturales involucran las actitudes y creencias de los estudiantes y docentes, confianza entre distintos sectores y valoración de la 
educación técnica, entre otros aspectos. Se trata de una definición no solo integral, sino también ambiciosa, pero que permite tener un norte para la indagación de experiencias nacionales y locales en material de articulación y la generación de lineamientos que apoyen el diseño de política pública.

Figura 2: Elementos de la definición de articulación propuesta

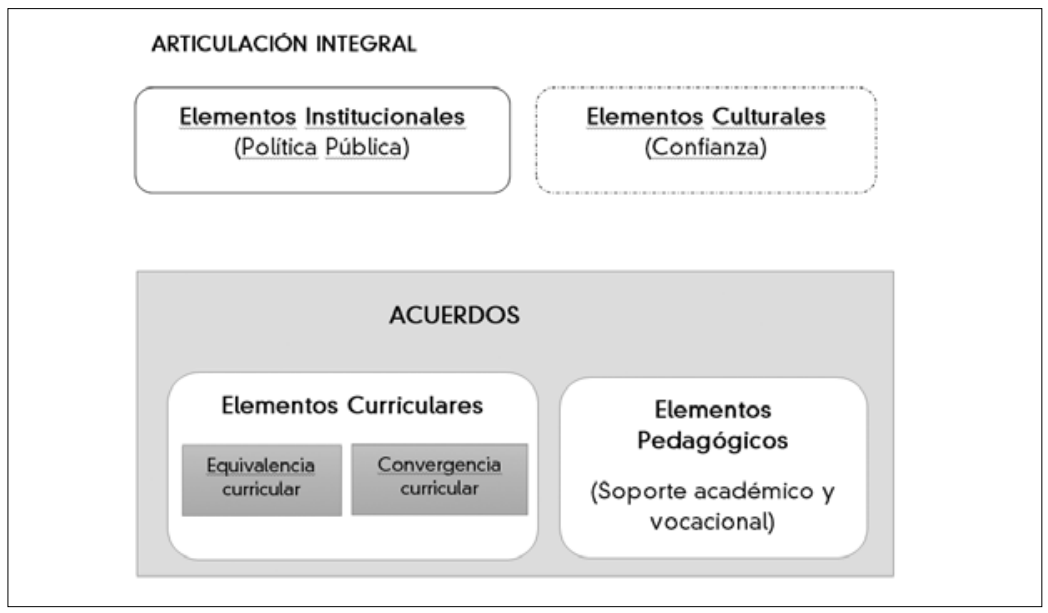

\subsection{Beneficios, barreras y facilitadores de la articulación}

La articulación entre instituciones de distintos niveles o sectores formativos genera una serie de beneficios reconocidos por la literatura, pero al mismo tiempo es limitada por distintas barreras, mientras que ciertas iniciativas o tendencias la facilitan.

En relación con los beneficios, la articulación permite la eficiencia en las transiciones a niveles superiores de educación o también a otros sectores paralelos. Cuando esta es bien realizada curricularmente, facilita la alineación de contenidos entre los programas educativos, disminuyendo el tiempo destinado al aprendizaje de un contenido específico, o bien, aumentando la cantidad y profundidad de contenidos cubiertos en un plazo determinado (Robertson-Smith, 1990). La articulación también reduce la incertidumbre de los alumnos y aumenta la legitimidad de sus trayectorias educativas. Asimismo, otorga estatus a la educación técnica de nivel secundario, 
porque los programas terminales que no entregan alternativas de continuidad de estudios posteriores a sus egresados tienen un rango menor que aquellos que sí lo hacen (Haas, 1999).

PhilippsKPA (2006) realiza una enumeración de los beneficios de la articulación, distinguiendo si estos son a nivel de sistema, institucional o del estudiante. En el primer caso, la articulación permite hacer frente más fácilmente a la escasez de personal calificado en algunas industrias, promoviendo ciertas cualificaciones desde el nivel escolar; fomenta mayores niveles de educación motivando la continuidad de estudios; y permite aumentar la eficiencia del sistema, reduciendo el gasto en educación, entre otros aspectos. A nivel institucional permite atraer más estudiantes; transferir a las instituciones escolares los conocimientos y competencias requeridos para el acceso a la educación superior, así como los criterios de éxito utilizados; facilitar el intercambio de recursos, las instalaciones y la experiencia; y crear nuevas oportunidades de investigación y trabajo colaborativo. Finalmente, a nivel de estudiante, la articulación amplía la combinación de habilidades, experiencia y comprensión que un estudiante tiene al momento de su graduación; reduce los costos reales y de oportunidad asociados con la obtención de titulaciones; y acorta los tiempos de titulación, aumentando las probabilidades de éxito de los estudiantes, entre una serie de otros beneficios.

Si bien la literatura tiende a centrarse en los beneficios de la articulación, es importante también mapear los posibles efectos no deseados que esta pueda tener. El principal problema es la canalización de buenos alumnos de la educación media hacia la vertiente técnica de nivel superior, sin considerar necesariamente sus intereses y conveniencia. Este problema es detectado por Farías (2013), quien sugiere que las decisiones de carrera de los alumnos son tomadas sin apoyo institucional, generándose una pérdida de capital humano, ya que alumnos de alto rendimiento y con bajo nivel socioeconómico podrían estar siendo conducidos por el sistema hacia carreras técnicas y desviados de la educación universitaria, donde podrían haber obtenido buenos resultados. De esta manera, un sistema con alto grado de articulación que permita una serie de trayectorias, requiere 
de sistemas de información y, sobretodo, de orientación vocacional que apoye la decisión de los alumnos.

Se debe considerar también que la articulación entre instituciones de educación secundaria y terciaria está condicionada por una serie de elementos que pueden convertirse en barreras que la limiten o incluso la imposibiliten. Al mismo tiempo, ciertas iniciativas o tendencias la pueden facilitar o promover. En el plano internacional, las barreras de la articulación han sido ampliamente examinadas por Robertson-Smith (1990) y PhilippsKPA (2006), entre otros. En el contexto nacional, Gaete y Morales (2011) identifican también los nudos críticos que podrían restringir los alcances de la articulación entre los niveles técnico superior, profesional y universitario. A partir de estas referencias y otras complementarias, los factores que dificultan la articulación se pueden agrupar en estructurales, culturales o sociales, curriculares, de financiamiento, de gestión, de competencia y de disparidad de poder. Estos factores se detallan en el Cuadro 1. 
Cuadro 1: Barreras que limitan la articulación en el ámbito de la ETP

\begin{tabular}{l|l}
\hline Factor & Barreras \\
\hline - Alta autonomía curricular y atomización de las instituciones de educación \\
superior que aumentan el número de conexiones a realizar para lograr \\
articulaciones. \\
- División administrativa estancada de los entes gubernamentales que genera \\
visiones incompletas o sesgadas acerca de los procesos de articulación. \\
- Ausencia de un marco de cualificaciones que ordene, categorice y comunique \\
las cualificaciones entregadas por los diferentes sectores y niveles de un \\
sistema educativo. \\
- Falta de un lenguaje o terminología común entre instituciones y actores \\
locales. \\
- Dispersión geográfica y baja densidad de instituciones educativas, tanto de \\
nivel escolar como de educación superior.
\end{tabular}

Finalmente los facilitadores de la articulación se refieren a todas las iniciativas públicas y privadas que apuntan a eliminar las barreras que obstaculizan las conexiones curriculares, pedagógicas, institucionales, pedagógicas y culturales entre los niveles secundario y postsecundario de la ETP. Entre estas iniciativas se destaca la declaración explícita de la articulación como objetivo a alcanzar por parte de autoridades educacionales nacionales y locales, así como también la instalación de un marco nacional de cualificaciones que establezca las conexiones curriculares entre distintos niveles y sectores 
de la ETP (PhillipsKPA, 2006). Por su parte, McKinney, Fields, Kurth y Kelly (1988) en un estudio acerca de los factores que contribuyen al logro de objetivos de los programas de articulación de la educación técnica, encontraron evidencia suficiente para los siguientes factores facilitadores:

- alta prioridad desde los mandos altos de las instituciones respecto de los acuerdos de articulación;

- relaciones personales efectivas y canales de comunicación abiertos entre los equipos de trabajo de las instituciones secundarias y postsecundarias;

- objetivos iniciales modestos para ser alcanzados con esfuerzo razonable;

- acuerdos de articulación bien escritos, estandarizados y formalizados; y

- disposición de servicios remediales para estudiantes que se favorecen de los acuerdos, entre otros aspectos.

\section{Revisión de experiencias de articulación de un conjunto de países}

La articulación de la ETP ha sido objeto de las políticas educativas de distintos países en su esfuerzo por proyectar a más estudiantes hacia el nivel postsecundario en áreas técnicas clave para el desarrollo de sus economías. Las políticas implementadas guardan relación con las características de sus sistemas de provisión de educación técnica, así como también del grado de regulación con el que operan sus sistemas educativos. En este punto se revisan las experiencias de cinco países -Estados Unidos, Australia, China, Colombia y España-seleccionados porque cuentan con distintos modelos de provisión de educación técnica en el nivel secundario -comprehensivos y segmentados- y grados de avance en la ordenación de su oferta formativa, es decir, un marco de cualificaciones.

Estados Unidos y Australia son países donde impera un modelo comprehensivo en el nivel secundario. En ambos casos, la ETP se imparte en el nivel secundario superior (grados 11 y 12) como una serie de cursos electivos que los estudiantes pueden tomar, junto con los créditos académicos obligatorios para la obtención del diploma 
de educación secundaria. Sin embargo en Australia, a diferencia de Estados Unidos, estos cursos permiten obtener una segunda certificación que es reconocida por la industria y por las instituciones postsecundarias que brindan formación técnica. En este país, la provisión de esta educación está regida desde el año 2000 por el Marco Australiano de Cualificaciones (AQF, por sus siglas en inglés) que conecta las certificaciones técnicas con las académicas otorgadas por las instituciones universitarias, en una única estructura que refleja la organización del sistema educativo de la nación. Asimismo, considera el reconocimiento de aprendizajes logrados en los puestos de trabajo a través de un entrenamiento estructurado. En cambio Estados Unidos no cuenta con un instrumento nacional de estas características, por lo que su oferta formativa es diversa como resultado de un profundo grado de descentralización y autonomía institucional (Kuczera \& Field, 2013).

En Australia, bajo el AQF, las cualificaciones de distintos niveles y sectores se ordenan en una secuencia conectada y flexible que permite a los estudiantes avanzar en su formación a través de la transferencia de créditos entre instituciones y el reconocimiento de aprendizajes previos. Formalmente, todo estudiante que ha cursado y certificado módulos iniciales en escuelas secundarias podría transferir créditos para cursos técnicos de nivel superior impartidos en instituciones especializadas. Sin embargo, para que ello ocurra los estudiantes deben cumplir con los requisitos de admisión exigidos, los que difieren en función del tipo de programas que ofrecen. Esto significa que el reconocimiento o transferencia de créditos adquiridos con anterioridad, podría no siempre estar disponible para la obtención de los diplomas avanzados en educación técnica. Asimismo, Misko (2006) señala que, en algunos casos, a los estudiantes se les solicita que vuelvan a cubrir ciertos contenidos más específicos, lo que refleja que en la práctica persiste la desconfianza desde las instituciones postsecundarias acerca de la idoneidad de los programas escolares para impartir sus módulos iniciales. Otra debilidad detectada es la falta de soporte vocacional brindada a los estudiantes de los centros escolares en la toma de decisiones durante la elección de sus cursos, por lo que se ha propuesto una severa reforma a su sistema de orientación vocacional (Watts, 2013). Pero la transferencia de 
96 ARTICULACIÓN DE LA EDUCACIÓN TÉCNICO PROFESIONAL: UNA CONTRIBUCIÓN PARA SU COMPRENSIÓN Y CONSIDERACIÓN DESDE LA POLÍTICA PÚBLICA - M. Sevilla, M. Farías y M. Weintraub

créditos no es la única estrategia con la que cuenta Australia para conectar los distintos niveles de su ETP: este país cuenta también con experiencias de instituciones multisectoriales que ofrecen programas de educación técnica tanto de nivel secundario como postsecundario, que se vinculan posteriormente con la educación universitaria. Estas instituciones se focalizan en jóvenes vulnerables de zonas rurales, en busca de mantenerlos en el sistema y proporcionarles un camino hacia la educación superior y el empleo (OECD, 2012).

Estados Unidos también ha realizado esfuerzos sistemáticos para conectar sus programas técnicos. Desde principios de los noventa impulsa el Programa TechPrep, que promueve la transición entre los niveles secundario y postsecundario principalmente en poblaciones de estudiantes que con menor probabilidad accederán a una carrera universitaria. El programa pide a los estados la creación de consorcios locales formados por escuelas secundarias, instituciones de educación superior, distritos escolares y representantes de la industria que cuenten con una serie de elementos entre los que se distinguen: acuerdos de articulación para impartir programas continuos entre los niveles secundario y postsecundario, estrategias de desarrollo docente, capacitación a consejeros y directivos de las instituciones y servicios de orientación vocacional. Bajo los principios de la teoría organizacional, el programa intentó integrar en una misma estructura los modelos de prestación de distintos niveles $y$, en última instancia, a las fuentes de trabajo remunerado. Sin embargo, la iniciativa ha tenido un historial modesto de efectividad, tanto en términos de cobertura como de resultados, principalmente porque en la práctica pocos consorcios llegaron a ofrecer planes de estudio completamente estructurados, más bien las instituciones que conforman los consorcios imparten programas de nivel secundario y postsecundario con poca coordinación (Dortch, 2012). Es por ello que los esfuerzos recientes en la materia han dispuesto de financiamiento federal para la promoción de iniciativas anexas al TechPrep, que promuevan la articulación entre los niveles secundario y postsecundario, como son las políticas de Programs of Study (POS), Career Cluster and Pathways, y Dual Enrollment. En particular, los POS se fundan en marcos curriculares referenciales (National Career Clusters) que proveen una estructura para la organización y provisión 
de programas ocupacionales integrados entre los niveles secundario y postsecundario y acentúan el rigor académico de los mismos (U.S. Department of Education, 2012).

Por su parte España, China y Colombia son ejemplos de países con modelos segmentados de provisión de educación técnica en el sistema escolar. En todos ellos, el acceso a esta educación es posterior a la conclusión de la secundaria inferior. De los tres países, China es el que tiene el sistema más selectivo, ya que un examen al término de este nivel es el que determina si el estudiante seguirá en la vía académica o en la técnica, mientras que en los otros países la opción se basa en las preferencias e intereses de los estudiantes. En lo referente a la educación superior, todos ellos cuentan con opciones técnicas postsecundarias bien establecidas que están abiertas tanto para egresados de programas escolares técnicos como académicos. En cambio, presentan distintos grados de avance en la ordenación de su oferta educativa a través de la presencia o ausencia de un marco nacional de cualificaciones, que prescriba en los distintos niveles y sectores los aprendizajes que deben alcanzarse. Por su parte España cuenta con un Sistema Nacional de Cualificaciones y Formación Profesional (SNCFP) que ordena las cualificaciones profesionales susceptibles de reconocimiento y acreditación, mientras que Colombia está avanzando en un sistema de ordenamiento de ocupaciones que es la base para un sistema de cualificaciones y China carece de un instrumento o sistema de similares características.

En España, el SNCFP juega un rol fundamental en la vinculación entre los distintos niveles formativos y en la definición de las posibles trayectorias formativas de los alumnos. Esto porque el sistema, al definir centralizadamente los programas de estudio, permite un mayor alineamiento de los contenidos técnicos de nivel secundario y postsecundario. Sin embargo, el sistema es criticado por la OECD por su falta de permeabilidad entre ambos niveles, ya que exige a los egresados de los programas técnicos volver a cursar un año de secundaria, pero en la vía académica, como requisito de acceso a la ETP de nivel postsecundaria (Musset \& Field, 2013). Otra crítica radica en el estancamiento que fácilmente tiende a producirse en la actualización de sus programas formativos y familias profesionales del 
98 ARTICULACIÓN DE LA EDUCACIÓN TÉCNICO PROFESIONAL: UNA CONTRIBUCIÓN PARA SU COMPRENSIÓN Y CONSIDERACIÓN DESDE LA POLÍTICA PÚBLICA - M. Sevilla, M. Farías y M. Weintraub

SNCFP, ya que requieren ser oficializados bajo la firma de un decreto real, lo que implica que los cambios deban realizarse también por un decreto del mismo nivel. Esta restricción exige acuerdos políticos y, por tanto, su actualización es lenta y compleja. Al igual que Australia, España también cuenta con centros educativos integrados que otorgan títulos técnicos tanto de nivel secundario como postsecundario, certifican competencias y ofrecen servicios de asesoría técnica. Su oferta programática se basa en el SNCFP y se construye en forma modular y flexible según las necesidades productivas locales. Estos centros tienen la ventaja de permitir concentrar en una sola institución conocimientos en temas específicos y la infraestructura apropiada.

China, por su parte, a fines de los noventa inició una estrategia deliberada para mejorar su sistema de educación técnica, eliminando el carácter terminal de los programas secundarios y vinculándolos con la educación superior, entre otros aspectos. La medida se concretó a través de la promulgación de una política formal que estableció mecanismos explícitos para la articulación entre los niveles secundario y postsecundario. El objetivo fue convertir a las escuelas técnicas en la principal fuente de matrícula de los programas técnicos postsecundarios y mejorar la eficiencia de esta formación incentivando la continuidad de carreras relacionadas o pertinentes a estudios previos. Asimismo, consideró la implementación de un sistema de conversión de puntos de créditos, a través del cual es posible reconocer los estudios anteriores para la continuidad de estudios superiores, tanto técnicos como universitarios (NCEVER, 2002). Tres son los modelos promovidos para conectar la ETP secundaria con la postsecundaria: continuos, segmentados y flexibles. Los modelos continuos tienen base en la escuela y unen en una sola institución la provisión de educación técnica secundaria y postsecundaria, logrando una mejor planificación curricular sin repetición de contenidos. Los modelos segmentados también tienen base en la escuela, pero se fundan en el reclutamiento de egresados de programas técnicos secundarios para su admisión en instituciones técnicas de nivel terciario, vía examinaciones. En este modelo es posible también el reconocimiento de aprendizajes previos a través del sistema de conversión de créditos, que convalida asignaturas con objetivos de aprendizaje y duración similar. Sin embargo, al no existir en este 
país un marco nacional de cualificaciones, la implementación del sistema de conversión de créditos está sujeta al criterio institucional y su aplicación no es uniforme. Finalmente, el modelo flexible se basa en examinaciones, al igual que el modelo segmentado, pero está abierto también a trabajadores que hayan adquirido competencias en contextos de formación no formales.

En lo que se refiere a Colombia, reformas recientes han puesto el foco en la pertinencia de articular su sistema educativo en todos sus niveles, en busca de mejorar la movilidad a lo largo del ciclo educativo y la inserción laboral de sus estudiantes, signando al Ministerio de Educación Nacional (MEN) como responsable de esta tarea. Sin embargo, estas leyes están limitadas por el ya consolidado concepto de autonomía de las instituciones de educación superior de este país, las que son finalmente las últimas responsables del reconocimiento de créditos desde el nivel secundario (CONPES, 2010). En particular, para concretar su mandato el MEN ha promovido en la ETP ofertas formativas con enfoque de competencias laborales y ha destinado recursos para la implementación de proyectos de fomento al tránsito hacia la educación superior desde los programas técnicos escolares. Entre ellos, una ley del año 2002 que autoriza a las instituciones técnicas de nivel superior a ofrecer programas de nivel secundario y también licenciaturas, si lo hacen en ciclos propedéuticos que permitan a sus estudiantes adquirir habilidades para el mercado laboral, pero también para enfrentar el siguiente nivel educativo. Con ello se fomentó la coordinación y articulación de currículos de distintos niveles, otorgando mayor permeabilidad al sistema. Una institución que contribuye en este país a la formación permanente de las personas es el SENA del Ministerio del Trabajo, que imparte gratuitamente programas técnicos, tecnológicos y complementarios. Esta institución mantiene diversas estrategias que permiten a los estudiantes de las escuelas técnicas capacitarse, certificarse y acceder directamente a programas de nivel postsecundario sin pasar por el proceso de selección regular. Finalmente, se destaca que recientemente este país está realizando esfuerzos importantes para instalar un marco nacional de cualificaciones, lo que ha llevado a que organismos internacionales como la OECD destaquen la capacidad de planificación del sistema colombiano (OECD y Banco Mundial, 2012). 
100 ARTICULACIÓN DE LA EDUCACIÓN TÉCNICO PROFESIONAL: UNA CONTRIBUCIÓN PARA SU COMPRENSIÓN Y CONSIDERACIÓN DESDE LA POLÍTICA PÚBLICA - M. Sevilla, M. Farías y M. Weintraub

El Cuadro 2 sintetiza las experiencias en materia de articulación de los países revisados. Una mirada transversal a los casos da cuenta de que en todos ellos, la articulación de la ETP es una meta relevante y se ejecutan estrategias concretas y variadas para alcanzarla. Estas estrategias se basan en distintos mecanismo de reconocimiento de aprendizajes, a los que en relación a los presentados en la Figura 2.1, se suma el de transferencias de créditos, propio de los sistemas con marcos de cualificaciones instalados.

Cuadro 2: Síntesis de experiencias internacionales

\begin{tabular}{|c|c|c|c|c|}
\hline $\begin{array}{c}\text { Modelo } \\
\text { Provisión ETP } \\
\text { secundaria } \\
\end{array}$ & País & $\begin{array}{l}\text { Políticas y } \\
\text { programas }\end{array}$ & $\begin{array}{l}\text { Mecanismo de } \\
\text { reconocimiento }\end{array}$ & $\begin{array}{c}\text { Aspectos relevantes } \\
\text { del país }\end{array}$ \\
\hline \multirow[t]{5}{*}{ Comprensivo } & \multirow[t]{2}{*}{ Australia } & $\begin{array}{c}\text { Marco } \\
\text { Cualificaciones } \\
\text { (AQF) }\end{array}$ & $\begin{array}{l}\text { Transferencias de } \\
\text { créditos }\end{array}$ & \multirow{2}{*}{$\begin{array}{l}\text { - Políticas pro tránsito } \\
\text { hacia la educación } \\
\text { superior } \\
\text { - Sólida estructura } \\
\text { institucional }\end{array}$} \\
\hline & & $\begin{array}{c}\text { Instituciones } \\
\text { Multisectoriales }\end{array}$ & $\begin{array}{l}\text { Convergencia } \\
\text { curricular }\end{array}$ & \\
\hline & \multirow[t]{3}{*}{$\begin{array}{l}\text { Estados } \\
\text { Unidos }\end{array}$} & Tech Prep & $\begin{array}{l}\text { Tránsito sin } \\
\text { reconocimiento } \\
\text { de aprendizajes o } \\
\text { convalidaciones } \\
\end{array}$ & \multirow[t]{3}{*}{$\begin{array}{l}\text { - Financiamiento ad } \\
\text { hoc } \\
\text { - Estrategias múltiples } \\
\text { para alinear niveles } \\
\text { ETP }\end{array}$} \\
\hline & & Program of Study & $\begin{array}{l}\text { Convergencia } \\
\text { curricular }\end{array}$ & \\
\hline & & Dual Enrollment & Equivalencia curricular & \\
\hline \multirow[t]{7}{*}{ Segmentado } & \multirow[t]{2}{*}{ España } & $\begin{array}{c}\text { Marco } \\
\text { Cualificaciones } \\
\text { (SNCFP) }\end{array}$ & $\begin{array}{l}\text { Transferencias de } \\
\text { créditos }\end{array}$ & \multirow{2}{*}{$\begin{array}{l}\text { - Alta importancia } \\
\text { al objetivo de } \\
\text { articulación } \\
\text { - Estructura curricular } \\
\text { burocrática }\end{array}$} \\
\hline & & Centros integrados & $\begin{array}{l}\text { Convergencia } \\
\text { curricular }\end{array}$ & \\
\hline & \multirow[t]{3}{*}{ China } & Modelo continuo & $\begin{array}{l}\text { Convergencia } \\
\text { curricular }\end{array}$ & \multirow{3}{*}{$\begin{array}{l}\text { - Articulación como } \\
\text { mandato legal } \\
\text { - Modelos diversos }\end{array}$} \\
\hline & & $\begin{array}{c}\text { Modelo } \\
\text { segmentado }\end{array}$ & $\begin{array}{l}\text { Equivalencia curricular } \\
\text { Exámenes } \\
\text { conocimientos } \\
\text { relevantes }\end{array}$ & \\
\hline & & Modelo flexible & $\begin{array}{l}\text { Exámenes } \\
\text { conocimientos } \\
\text { relevantes }\end{array}$ & \\
\hline & \multirow[t]{2}{*}{ Colombia } & $\begin{array}{c}\text { Ciclos } \\
\text { propedéuticos }\end{array}$ & $\begin{array}{l}\text { Convergencia } \\
\text { curricular }\end{array}$ & \multirow{2}{*}{$\begin{array}{l}\text { - } \text { Coherencia } \\
\text { de políticas y } \\
\text { planificación a LP } \\
\text { - Presencia nacional } \\
\text { de institución pública } \\
\text { (SENA) }\end{array}$} \\
\hline & & Proyectos SENA & $\begin{array}{l}\text { Tránsito sin } \\
\text { reconocimiento } \\
\text { de aprendizajes o } \\
\text { convalidaciones }\end{array}$ & \\
\hline
\end{tabular}




\section{Análisis de experiencias nacionales de vinculación entre la EMTP y la ESTP}

\subsection{El contexto chileno}

En Chile la EMTP concentra al $41 \%$ de la matrícula de los dos últimos años de educación media, mientras que la Enseñanza Media Científico Humanista (EMCH) convoca al 59\% restante. Se imparte principalmente en establecimientos del sector municipal y particular subvencionado, aunque los establecimientos administrados por corporaciones de administración delegada juegan también un rol importante en la provisión de este tipo de educación. La ESTP, por su parte, que abarca a las carreras técnicas y a las carreras profesionales sin licenciatura, se ofrece principalmente en Centros de Formación Técnica (CFT) e Institutos Profesionales (IP), aunque las universidades también están facultadas para impartirlas. Una de las principales características de este sector es la acentuada concentración de su matrícula en unas pocas instituciones ${ }^{6}$. Otro rasgo relevante es la autonomía con la que cuentan las instituciones para definir su oferta curricular, lo que lleva a una amplia diversidad de carreras, títulos asociados y programas de estudio. En cambio la oferta de la EMTP es acotada y está definida centralizadamente por el Ministerio de Educación.

Una tendencia reciente, tanto en la EMCH como en la EMTP, son las mayores tasas de continuidad de estudios que exhiben sus egresados. Según la Figura 3, entre las cohortes de egreso 2005 y 2012, la proporción de estudiantes que accede a la educación superior en los dos primeros años se incrementó de un 70\% a un $87 \%$ para el primer grupo, mientras que los técnicos profesionales lo hicieron de un 30\% a un $52 \%$. Estas cifras dan cuenta que de mantenerse relativamente estable el balance entre estudiantes EMCH y EMTP, los egresados de esta última modalidad son los que más significativamente pueden contribuir a la expansión de la educación superior en los próximos años. Por otra parte, el análisis detallado de las bases de datos que resultan de la conexión de los registros de los programas escolares

6 En el 2013, el 56\% de la matrícula de los CFT se concentró en dos instituciones, mientras que tres IP albergaron a cerca del $55 \%$ de estudiantes adscritos a este tipo de establecimientos. 
con los de la educación superior, da cuenta que cerca del 80\% de los egresados EMTP de la cohorte de 2012 que continuaron estudios lo hicieron en carreras de la ESTP. De este total un 46\% ingresó a aquellas directamente relacionadas con sus estudios técnicos previos.

Figura 3: Tasa de estudiantes que continúan estudios superiores al cabo de dos años según tipo de educación. Cohortes de egreso 2005-2012

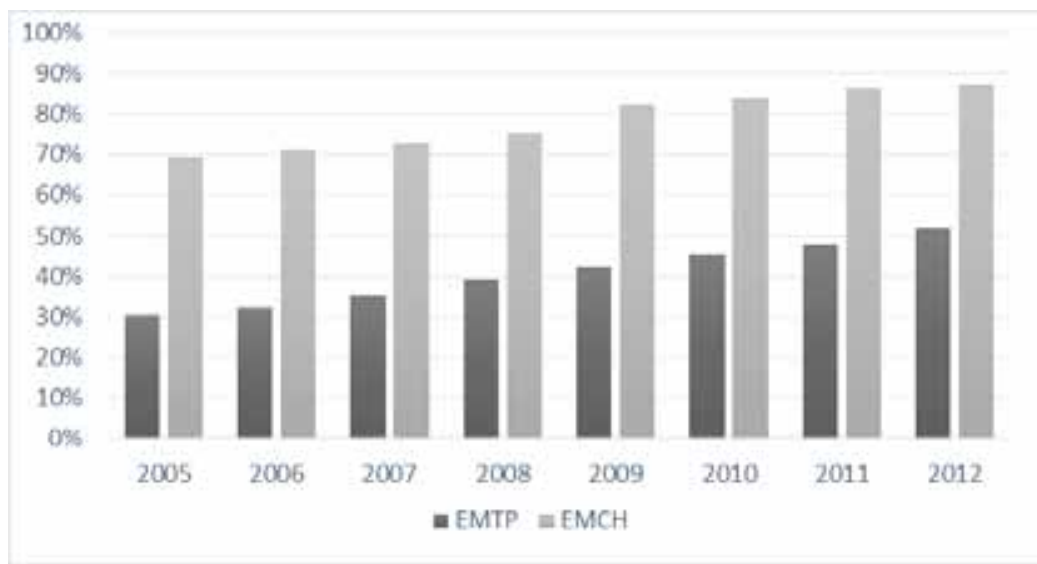

Fuente: Elaboración propia a partir de datos de Mineduc.

Sin embargo, pese a las tasas crecientes en las que los egresados de la EMTP están accediendo a la ESTP, la legislación del sistema educativo (Ley General de Educación ${ }^{7}$, LGE) que, entre otros aspectos, fija los requisitos mínimos que deben exigirse en cada nivel educativo, no hace referencia a convalidaciones entre estos niveles. En cambio, sí explicita y regula la convalidación de cursos realizados en el extranjero, el reconocimiento de cursos realizados en el mismo nivel (es decir, en otra institución de ESTP) y de los aprendizajes adquiridos fuera del sistema educativo. A esta omisión se suma la forma en la que la legislación define los requisitos para la obtención del título de Técnico de Nivel Superior (TNS) que dicen relación con un número mínimo de clases y no con el logro de competencias y aprendizajes, lo que dificulta la articulación entre niveles y la instalación de un marco nacional de cualificaciones. Se destaca también que dentro de los principios inspiradores de la LGE no se encuentra ninguno asociado al

7 Ley 20.370 de 2009. 
concepto de "eficiencia" de la trayectoria educativa de las personas que llame a evitar la exposición a conocimientos que ya fueron adquiridos, a través del reconocimiento, o bien, la convalidación de aprendizajes previos entre dos niveles consecutivos.

Finalmente, como parte del contexto en el que se realiza el estudio de casos de experiencias de vinculación entre niveles de la ETP se da cuenta que, en los años recientes, diversos fondos públicos concursables se han puesto a disposición de las instituciones de ESTP para establecer o fortalecer sus nexos con los liceos EMTP y, de esa forma, facilitar la continuidad de estudios de sus egresados. A nuestro juicio, si bien estos fondos han permitido la inyección de recursos públicos a iniciativas institucionales puntuales, no se han concebido como propuestas de políticas de articulación sistémicas que permitan avanzar en el establecimiento de conexiones formales entre los niveles secundario y terciario.

\subsection{Aspectos metodológicos}

En busca de recabar desde los propios actores educacionales la relevancia que estos otorgan a la articulación y las iniciativas que han realizado para avanzar en este desafío en el contexto antes expuesto, se revisaron experiencias de vinculación entre instituciones de EMTP y ESTP en el ámbito nacional. Para ello se utilizó la metodología de estudio de casos que permite comprenden y profundizar cada experiencia abordada, mediante una aproximación a su singularidad y complejidad, así como a su inserción e interrelación con el contexto (Stake, 1999). Atendiendo a esta metodología, se aplicaron entrevistas en profundidad con los actores responsables de la vinculación en las instituciones involucradas. La selección de los casos correspondió a una muestra intencionada, a fin de incorporar experiencias distintas gestadas por instituciones con diverso perfil. Los cuatro primeros casos se analizaron desde la perspectiva de la institución de ESTP, mientras que los dos restantes desde la visión de los establecimientos educacionales, recabada a través de su entidad sostenedora y el propio centro escolar. El Cuadro 3 entrega el detalle de los seis casos estudiados. 
104 ARTICULACIÓN DE LA EDUCACIÓN TÉCNICO PROFESIONAL: UNA CONTRIBUCIÓN PARA SU COMPRENSIÓN Y CONSIDERACIÓN DESDE LA POLÍTICA PÚBLICA - M. Sevilla, M. Farías y M. Weintraub

Cuadro 3: Muestra de casos

\begin{tabular}{|c|c|c|c|}
\hline $\begin{array}{c}\text { Perspectiva } \\
\text { de análisis }\end{array}$ & Caso & Características & Entrevistados \\
\hline \multirow{4}{*}{ ESTP } & 1 & $\begin{array}{l}\text { Institución ESTP con presencia a nivel } \\
\text { nacional y vinculación con gran número } \\
\text { de liceos EMTP. }\end{array}$ & $\begin{array}{l}\text { ESTP: nivel central y sede. } \\
\text { EMTP: dirección del } \\
\text { establecimiento. }\end{array}$ \\
\hline & 2 & $\begin{array}{l}\text { Institución ESTP con presencia nacional } \\
\text { y vinculada institucionalmente con un } \\
\text { liceo EMTP. }\end{array}$ & $\begin{array}{l}\text { ESTP: nivel central y sede. } \\
\text { EMTP: dirección del } \\
\text { establecimiento. }\end{array}$ \\
\hline & 3 & $\begin{array}{l}\text { Institución ESTP que nace vinculada } \\
\text { institucionalmente con un liceo EMTP. }\end{array}$ & ESTP: nivel central. \\
\hline & 4 & $\begin{array}{l}\text { Institución ESTP regional y liceo EMTP } \\
\text { enfocados a un sector productivo } \\
\text { específico. }\end{array}$ & $\begin{array}{l}\text { ESTP: sede. } \\
\text { EMTP: dirección del } \\
\text { establecimiento. }\end{array}$ \\
\hline \multirow{2}{*}{ EMTP } & 5 & $\begin{array}{l}\text { Entidad sostenedora EMTP enfocada a } \\
\text { especialidades con alta cobertura de } \\
\text { matrícula y con vinculaciones incipientes } \\
\text { con instituciones ESTP. } \\
\end{array}$ & $\begin{array}{l}\text { ESTP: nivel central. } \\
\text { EMTP: entidad sostenedora y } \\
\text { dirección establecimiento. }\end{array}$ \\
\hline & 6 & $\begin{array}{l}\text { Entidad sostenedora EMTP enfocada } \\
\text { a especialidades con baja cobertura } \\
\text { de matrícula y con vinculaciones } \\
\text { consolidadas con instituciones ESTP. }\end{array}$ & $\begin{array}{l}\text { ESTP: nivel central. } \\
\text { EMTP: entidad sostenedora y } \\
\text { dirección establecimiento. }\end{array}$ \\
\hline
\end{tabular}

\subsection{Principales hallazgos}

Una primera mirada transversal a los casos examinados da cuenta de que aún en ausencia de una política pública que releve a la articulación como aspecto clave para el mejoramiento de la educación técnica, las instituciones de ESTP han avanzado en establecer vínculos con los liceos de EMTP. Sin embargo, se trata de vinculaciones que, junto con considerar acciones con el foco puesto en la captación de estudiantes, tienden a restringirse en el mejor de los casos a elementos curriculares. En particular, se identifica que las instituciones han trasladado la lógica de convalidación de asignaturas o módulos al interior de la educación superior, a los procesos de reconocimiento de aprendizajes desde la EMTP hacia la ESTP, apelando a su autonomía institucional. Por consiguiente, los mecanismos más frecuentes son los exámenes de conocimientos relevantes y la convalidación de asignaturas, los que en general se gestan en el marco de convenios de colaboración institucional. Solo algunos casos han incursionado en procesos de 
convergencia curricular, es decir, de diseño o ajuste conjunto de programas de estudio.

Todas las iniciativas indagadas son recientes y las instituciones no cuentan con información que permitan dar cuenta de sus resultados. Por otra parte, se evidenció que en todos los casos abordados, los procesos de admisión de estudiantes con reconocimiento de aprendizajes acontecen sin el soporte pedagógico necesario para apoyar el acceso y permanencia en sus carreras.

El Caso 1 que corresponde a una institución ESTP con presencia a nivel nacional y vinculación con gran número de liceos EMTP es el que presenta los mayores avances. Esta institución ha formalizado y regulado las vinculaciones de sus distintas sedes con los establecimientos de educación media del país, a través de la creación de una unidad centralizada responsable de estandarizar y potenciar dichos vínculos. El procedimiento que se ha establecido en materia de articulación contempla el trabajo conjunto con liceos técnico profesionales, tanto para efectuar procesos de equivalencia curricular o convergencia curricular que permitan convalidar directamente asignaturas. Esta institución de ESTP, también utiliza los exámenes de conocimientos relevantes como mecanismo de convalidación de asignaturas, con estudiantes de liceos con vínculos incipientes.

El Caso 2 que se refiere a una institución ESTP con sedes a lo largo del país, si bien ofrece también la posibilidad de convalidar asignaturas en el marco de convenios de colaboración institucionales, lo hace solo con un número acotado de establecimientos de la EMTP y exigiendo un examen de conocimientos relevantes a los alumnos, de cuyos resultados depende esta opción. Esta institución tiene además la particularidad de haber fundado bajo su alero un establecimiento de EMTP, cuya infraestructura es compartida con una de sus sedes en distintas jornadas. Con este establecimiento, la vinculación institucional acontece automáticamente, ya que comparten el mismo soporte administrativo. En cambio, en el plano curricular la convergencia entre los programas de estudio de nivel medio y superior que se logró en una primera etapa se perdió por la distinta periodicidad de los ajustes de las mallas de estudio. No 
106 ARTICULACIÓN DE LA EDUCACIÓN TÉCNICO PROFESIONAL: UNA CONTRIBUCIÓN PARA SU COMPRENSIÓN Y CONSIDERACIÓN DESDE LA POLÍTICA PÚBLICA - M. Sevilla, M. Farías y M. Weintraub

obstante, al momento de la realización de las entrevistas, ambas instituciones se encontraban trabajando en el ajuste de los programas de estudio del liceo de EMTP, en vistas a que sus egresados puedan optar por la convalidación directa de asignaturas en la institución superior. La gran masa crítica de estudiantes que se podrían beneficiar de las convalidaciones justifican los procesos de convergencia curricular, ya que al menos el $50 \%$ de los egresados de cada cohorte del establecimiento se matricula en sedes de la ESTP en carreras relacionadas con su especialidad de egreso. Esta institución de ESTP también ha realizado procesos de convergencia curricular, con liceos EMTP de otras instituciones sostenedoras en el marco de proyectos de articulación puntuales financiados por el Ministerio de Educación.

El Caso 3, a diferencia del anterior tiene una génesis inversa: se refiere a una institución de ESTP que fue creada al alero de una entidad sostenedora de liceos EMTP para aprovechar la infraestructura existente, los recursos docentes y potencialmente canalizar a una proporción de sus egresados. Sin embargo, en los primeros años de funcionamiento de la institución de ESTP, muy pocos egresados de los liceos vinculados optaron por continuar estudios superiores en la institución, principalmente porque hacerlo significaba para ellos prolongar su escolaridad, al permanecer en el mismo edificio y con los mismos docentes. Tampoco tenían el incentivo de convalidación de asignaturas, ya que la institución de ESTP no consideró procesos de equivalencia o convergencia curricular con los programas de estudio de los liceos de la entidad sostenedora. A juicio de los entrevistados de este caso, el cambio de paradigma de pasar de una institución escolar a una de educación superior fue lento y difícil, lo que sumado a problemas en la planificación y financiamiento del proyecto, llevaron al cierre de la institución de ESTP.

El Caso 4, por su parte, a diferencia de los casos 1 y 2, da cuenta de un proceso abierto que una institución de ESTP ha iniciado para que los egresados de liceos EMTP de su entorno geográfico convaliden individualmente asignaturas que corresponden a carreras y especialidades para un sector productivo específico de la región. Se trata de un modelo flexible de convalidación que no requiere de la suscripción de convenios institucionales y que se gesta a partir de 
los resultados de un proyecto de articulación tripartito ejecutado con fondos públicos, que involucró a la institución de ESTP, una entidad sostenedora de EMTP y el sector productivo. En este proyecto, se revisaron en conjunto los programas de estudio del nivel secundario y postsecundario, estableciéndose contenidos comunes relevantes. Sin embargo, bajo el actual esquema, el vínculo institucional entre liceos EMTP y la institución postsecundaria en cuestión es débil, limitado a charlas de difusión sin incursionar en los planos curriculares ni pedagógicos, lo que deja sin soportes adecuados a los estudiantes que se benefician de estas convalidaciones.

Los últimos dos casos examinados se abordan desde las instituciones sostenedoras de liceos EMTP. En particular, el Caso 5 se refiere la experiencia de una entidad sostenedora cuyos establecimientos bajo su dependencia mantienen vínculos con varias instituciones ESTP, que corresponden a las que con mayor frecuencia matriculan a sus egresados. Sin embargo, dichas vinculaciones se circunscriben a charlas de orientación vocacional, capacitación docente y rebaja de aranceles. Solo se ha logrado visualizar con una institución de educación superior la suscripción de acuerdos que, en un futuro, se espera que permitan convalidaciones directas de asignaturas para los egresados de sus liceos. Los limitados avances de este caso se deben principalmente a que en el pasado el acercamiento a las instituciones de educación superior lo realizaban los liceos de manera independiente y no la entidad sostenedora como representante de todos ellos.

De distinto modo, el Caso 6 rescata la experiencia de una entidad sostenedora que congrega un número relevante de establecimientos de un sector productivo particular que tiene injerencia en su dirección y administración. Esta entidad posee un equipo técnico pedagógico a nivel central que da apoyo a sus establecimientos con el diseño de planes y programas propios y estrategias para su implementación. Esto le otorga un estatus distinto cuando inicia conversaciones para avanzar en procesos de articulación con instituciones de ESTP. La experiencia puntual revisada se refiere al trabajo colaborativo que esta entidad inició para identificar la equivalencia curricular de sus programas con las mallas de una institución específica y que se 

PARA SU COMPRENSIÓN Y CONSIDERACIÓN DESDE LA POLÍTICA PÚBLICA - M. Sevilla, M. Farías y M. Weintraub

tradujo en la posibilidad de generar convalidaciones estructuradas y directas de asignaturas de primer y segundo semestre, acortando la carrera hasta en un año. Sin embargo, nuevamente se trata de un proceso reciente, por lo que solo un bajo número de estudiantes se ha beneficiado de las convalidaciones.

A modo de síntesis, el Cuadro 4 detalla los elementos de vinculación identificados en los seis casos abordados, los que en general como ya se mencionó corresponden a iniciativas específicas que se han gestado solo en el último tiempo. Como se aprecia, las actividades involucradas van desde aspectos de carácter colaborativo incipiente (como becas o rebajas arancelarias), hasta la convalidación directa de asignaturas que resulta de procesos de la equivalencia y convergencia curricular ejecutados en el marco de convenios de colaboración.

Cuadro 4: Elementos de vinculación EMTP-ESTP identificados en los casos nacionales

\begin{tabular}{|c|c|c|c|c|c|c|c|c|c|}
\hline \multirow{2}{*}{\multicolumn{4}{|c|}{ Elementos identificados }} & \multicolumn{6}{|c|}{ Casos } \\
\hline & & & & 1 & 2 & 3 & 4 & 5 & 6 \\
\hline \multirow{5}{*}{ 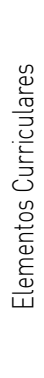 } & \multicolumn{3}{|c|}{ Sin convalidación o reconocimiento de asignaturas } & & & $X$ & & & \\
\hline & \multirow{4}{*}{ Con convalidación } & \multicolumn{2}{|c|}{$\begin{array}{l}\text { Exámenes de reconocimientos } \\
\text { relevantes }\end{array}$} & $x$ & $x$ & & & $x$ & \\
\hline & & \multicolumn{2}{|c|}{$\begin{array}{l}\text { Convalidaciones individuales caso } \\
\text { a caso }\end{array}$} & & & & $X$ & & \\
\hline & & \multirow{2}{*}{$\begin{array}{l}\text { Articulación } \\
\text { Curricular }\end{array}$} & $\begin{array}{l}\text { Equivalencia } \\
\text { curricular }\end{array}$ & $x$ & $x$ & & $X$ & & $X$ \\
\hline & & & $\begin{array}{l}\text { Convergencia } \\
\text { curricular }\end{array}$ & $x$ & $x$ & & & & \\
\hline \multirow{6}{*}{ 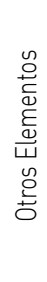 } & \multicolumn{3}{|l|}{ Soporte académico } & & & & & & \\
\hline & \multicolumn{3}{|c|}{ Orientación vocacional } & $x$ & & & & $x$ & \\
\hline & \multicolumn{3}{|c|}{ Financiamiento Público } & & $x$ & & $x$ & & \\
\hline & \multicolumn{3}{|c|}{ Participación Sector Productivo } & & & & $x$ & & $x$ \\
\hline & \multicolumn{3}{|c|}{ Verticalidad institucional } & & $x$ & $x$ & & & \\
\hline & \multicolumn{3}{|c|}{ Becas o rebajas de aranceles } & $x$ & & & & $x$ & \\
\hline
\end{tabular}

Por otra parte, se sustrae del estudio de casos que para las instituciones de ESTP una de las principales motivaciones para avanzar en acuerdos de articulación es que a través de esta vía pueden atraer 
estudiantes vocacionalmente cautivos desde los liceos de EMTP, es decir, a estudiantes que al haber cursado en la educación media una especialidad técnica relacionada con sus carreras, poseen ya cierto grado de convicción vocacional. Esto es altamente relevante, dadas las altas tasas de deserción que la ESTP exhibe. Por su parte, la motivación principal a nivel de sostenedores y establecimientos educativos, estaría en propiciar la continuidad de estudios de sus egresados, lo que repercute en su prestigio institucional.

Junto con lo anterior se rescata que durante las entrevistas realizadas, los actores indicaron una serie de beneficios de la vinculación, los cuales en general coinciden con los identificados por la literatura. Estos beneficios provienen de sus creencias y expectativas, más que de sus experiencias concretas obtenidas recientemente. Así se tiene que según los entrevistados, una de las principales bondades de la articulación es su potencial de reducir los tiempos y costos asociados a la obtención de una carrera superior, siendo un factor de incentivo para la continuidad de estudios, especialmente para alumnos provenientes de los primeros quintiles de ingreso.

En relación con las barreras que los actores vislumbran para avanzar en materia de articulación de la ETP, se aprecia una coincidencia importante con aquellas identificadas en la literatura, destacando su acuerdo al señalar la ausencia de un marco nacional de cualificaciones como la piedra de tope: a su juicio, sin este instrumento los esfuerzos que se deben realizar resultan extensos y poco efectivos, ya que se debe avanzar caso a caso. Asimismo, los actores son conscientes respecto de las restricciones que la misma Ley General de Educación (LGE) les pone para avanzar en convalidaciones directas para los estudiantes, por lo que hacen uso de sus reglamentos internos. Por otra parte, apuntan como una barrera importante las restricciones que imponen las ayudas estudiantiles (becas y créditos), al condicionar su otorgamiento al mantenimiento de una carga horaria mínima durante todo el periodo de estudio en la ESTP. Otra limitación financiera son los altos costos que implican los procesos de equivalencia y convergencia curricular en términos del tiempo de los profesionales de las instituciones, lo que se convierte en una restricción especialmente para los liceos de 
EMTP, que tienen las horas de su personal acotadas y sin posibilidad de incrementarse. Se señala también como obstaculizador de la apropiación de los beneficios de la articulación, el traslape en la temporalidad de los procesos de titulación de EMTP y de admisión y matrícula en ESTP, lo cual restringe para el alumno las posibilidades de optar a la convalidación de asignaturas. Finalmente, desde las instituciones superiores se indica que mantienen procesos continuos de actualización de sus mallas curriculares, mientras que en la educación secundaria existen rigideces para modificar sus planes de estudio en plazos similares a las instituciones de educación superior. Por su parte, desde los sostenedores y liceos de EMTP se acusa una baja voluntad, y desconocimiento y/o bajo reconocimiento por parte de las instituciones postsecundarias, de sus esfuerzos por entregar una formación técnica de calidad.

\section{Conclusiones y recomendaciones de política}

Bajo el nuevo enfoque de la ETP de nivel secundario que resalta su finalidad propedéutica y la ratifica como una opción que conduce también a la educación superior, el discurso de esta educación solo puede mantenerse en la medida en que se fortalezca su nexo con la formación general y se articule con la educación técnica postsecundaria. Así lo han entendido diversos países y han sustentado la nueva orientación de sus programas técnicos escolares con mandatos legales que explícitamente han señalado a la articulación como una meta por alcanzar.

La revisión de las experiencias internacionales da cuenta de que se trata de un desafío complejo y que son múltiples los ámbitos que se deben abordar para propiciar el tránsito eficiente y exitoso de los egresados de la educación técnica de nivel secundario hacia la educación superior. En el ámbito curricular, aparece como clave la instalación de un marco de cualificaciones, pero la experiencia de Australia indica que incluso en presencia de este instrumento, la confianza entre los centros escolares y las instituciones postsecundarias resulta clave. Asimismo, del caso español se sustrae que la burocracia para mantener actualizado este instrumento puede convertirse en una barrera importante. Tanto el caso australiano como el español sugieren 
que este instrumento no es una receta mágica que resuelve el problema de la articulación, aproximándose más a ser una acción necesaria, pero insuficiente para mejorar la permeabilidad de los programas técnicos. Por otra parte, la experiencia reciente de Estados Unidos a través de los POS (Programs of Study) da cuenta que iniciativas de menor envergadura como los marcos curriculares referenciales para los proveedores de educación técnica de los niveles secundario y postsecundario, pueden ser también estrategias adecuadas para facilitar la articulación curricular de ambos niveles. En materia de apoyo pedagógico y vocacional a los estudiantes, el Programa TechPrep de Estados Unidos aparece como una estrategia que aborda de buena manera estos ámbitos, aunque falla en la conexión curricular entre niveles. Asimismo, se advierte también que integrar la provisión de formación técnica de nivel secundario con la de postsecundaria en una sola institución es también un camino que favorece la articulación entre ambos niveles y que es seguido en tres de los cinco países revisados (Australia, China y España). Finalmente, el caso colombiano muestra cómo puede avanzarse definidamente en esta materia y pone una nota de alerta sobre la lentitud y falta de decisión que Chile está teniendo al respecto.

En nuestro país, la articulación de la ETP es todavía un desafío pendiente y reiterado como urgente tanto por los actores locales como por distintos informes nacionales e internacionales. A nuestro juicio, la urgencia de la articulación se justifica por dos razones. La primera, porque es la población más vulnerable la que está valorando y eligiendo la EMTP actualmente y son ellos a los que se quisiera motivar en mayor medida para que progresen en el sistema educativo. La segunda razón es que las economías están buscando todas las estrategias para aumentar su acervo de capital humano y es en los sectores de educación masiva -no en los de elite- donde se juega este aumento. Sin embargo, una revisión al marco legal vigente que rige el sistema educativo chileno da cuenta de que es esta legislación la que no favorece los avances en materia de articulación. Una serie de artículos de esta ley que resultan claves para este desafío están definidos en forma imprecisa o no están presentes. A pesar de estas limitaciones, se evidencia que el incremento sostenido en el tiempo de las tasas de acceso a las carreras de la ESTP desde la EMTP ha 
112 ARTICULACIÓN DE LA EDUCACIÓN TÉCNICO PROFESIONAL: UNA CONTRIBUCIÓN PARA SU COMPRENSIÓN Y CONSIDERACIÓN DESDE LA POLÍTICA PÚBLICA - M. Sevilla, M. Farías y M. Weintraub

favorecido la promoción de acuerdos de articulación. Este hecho hace que los recursos a invertirse con este propósito puedan ser más costoefectivos al beneficiar a una población mayor de estudiantes, mientras que otros grupos de estudiantes pueden verse también motivados a seguir estudios posecundarios al evidenciarse que sus aprendizajes previos les son reconocidos.

Del estudio de casos locales se rescata que los procesos de vinculación de los niveles secundario y postsecundario aún resultan precarios en Chile y que carecen de una visión sistémica. En un escenario donde no existe ni se vislumbran tentativas de levantar una política nacional que llegue a todo el sistema, los casos estudiados responden más bien a iniciativas aisladas que apuntan netamente a aspectos curriculares y que se resuelven uno a uno. El estudio sugiere que la motivación desde las instituciones de ESTP para avanzar en materia de articulación apunta, principalmente, a captar una matrícula vocacionalmente cautiva desde los liceos EMTP, con menos riesgos de deserción por desencantamiento de las carreras, más que a facilitar e incentivar el tránsito eficiente de los estudiantes entre ambos niveles. Por otra parte, se identifica que instituciones sostenedoras de liceos EMTP con equipos técnicos bien conformados y planes y programas propios, resultan más atractivas para iniciar procesos de articulación en comparación con los liceos que aisladamente desean incursionar en estos procesos con alguna institución de ESTP que brinde carreras vinculadas con su oferta de especialidades. Asimismo, el estudio de casos muestra que existe una ilusión entre los actores en torno a la articulación, ya que los beneficios que le atribuyen corresponden más a nociones teóricas que a su propia experiencia. Aunque declaran que llevan varios años trabajando en procesos de vinculación, la mayoría de las experiencias de articulación curricular que pueden ser catalogadas como tales, son relativamente nuevas y experimentales. Por ende, las instituciones aún no pueden dar cuenta de su efectividad y tampoco logran estimar el número de beneficiados. Finalmente, se señala que si bien algunos casos han contado en algún momento con recursos públicos para avanzar en sus procesos de articulación, los costos recaen principalmente en las propias instituciones, en circunstancias donde los potenciales beneficios de la articulación son apropiables socialmente. 
La revisión de experiencias internacionales y el estudio de casos en Chile sugieren que el proceso de transición entre la educación secundaria y la educación terciaria presenta importantes debilidades que dificultan y entorpecen el acceso y éxito en la educación superior. La falta de políticas de convalidación curricular estructurada, de apoyo a la decisión vocacional y de soporte pedagógico en la educación superior, sumadas a la debilidad de la normativa, dejan al proceso de transición como un espacio de competencia por captación de clientes, más que como un espacio de consolidación de decisiones vocacionales que combine el mayor beneficio para el alumno y el desarrollo productivo y social del país. Esta pérdida de oportunidades puede aumentar el descontento y convertirse en una traba para el desarrollo del país. Esta conclusión final, valida nuestra propuesta de definición que conceptualiza la articulación desde una perspectiva amplia, que pone su foco no solo en la transición entre la educación secundaria y la terciaria, sino también en el éxito en este último nivel.

A la luz de los hallazgos encontrados, se proponen las siguientes recomendaciones de política:

1. Declarar a la articulación como uno de los ejes fundamentales del fortalecimiento de la ETP y como prioridad de política, invirtiendo recursos en estrategias concretas para avanzar en ello.

2. Enmendar la $\mathrm{LGE}^{8}$, incluyendo dentro de sus principios orientadores el de "eficiencia en las trayectorias formativas" y admitiendo convalidaciones entre distintos niveles educativos, para ello debiera considerarse la noción de "logro de aprendizajes" y no el de "número y horas de clase".

3. Como parte de una política de Estado, construir e instalar un marco de cualificaciones que integre los distintos niveles y sectores del sistema educativo chileno. Sin embargo, considerando que se trata de una estrategia de largo plazo, se propone avanzar en el corto y mediano plazo en la construcción de marcos curriculares referenciales que integren perfiles de egreso de nivel secundario y postsecundario, en planes y programas únicos para ser impartidos en los liceos EMTP y puestos a disposición de las instituciones de ESTP.

8 Los autores comprenden la dificultad de este cambio, sin embargo, deciden mencionarlo dejando a los diseñadores de políticas evaluar su factibilidad. 
4. En concordancia con la definición de articulación propuesta, diseñar estrategias múltiples para avanzar en los procesos de articulación de la educación técnica secundaria y postsecundaria desde una perspectiva integral que considere no solo elementos curriculares, sino también pedagógicos, vocacionales y de apoyo institucional. Es urgente desarrollar una política de orientación vocacional que considere al menos todo el ciclo de la educación secundaria.

5. Contemplar dentro de las estrategias, iniciativas que apunten a la integración institucional de la ESTP en sus distintos niveles, ya sea en nuevas instituciones que nazcan con esa figura, o bien, acoplando a las instituciones postsecundarias los dos últimos años de formación diferenciada de EMTP. Los nuevos CFT públicos pueden jugar un rol clave en este sentido. No parece pertinente considerar la extensión hacia la ESTP de los establecimientos de EMTP.

6. Buscar la forma de aglutinar establecimientos EMTP para aumentar su poder de negociación con las instituciones de ESTP. El diseño de la nueva institucionalidad de educación pública debiera considerar este elemento en su diseño.

7. Finalmente, monitorear los procesos y resultados de las estrategias de articulación a implementarse a través de investigaciones independientes, con metodologías sólidas y cuyos resultados sean de conocimiento público.

\section{Bibliografía}

Cáceres, E. (2007). Educación superior en Chile: diversidad, diversificación, ¿ahora articulación? Revista Calidad en la Educación, 26(1), 117-132.

Carmichael, M., Hall, T., \& O'Meara, R. (2007). A discussion of past, present, and future articulation models at postsecondary institutions. Journal of Technology Studies, 33(1-2), 9-15.

Castro, E. y Orellana, W. (2010). La educación media técnico profesional en Chile: entre la desarticulación y la indefinición. Intersecciones educativas, 2, 73-81.

Centro Europeo para el desarrollo de la formación profesional, Cedefop (2014). Attractiveness of initial vocational education and training: identifying 
what matters. Research Paper $N^{\circ}$ 39. Luxembourg: Publications Office of the European Union.

Clark, W. (1998). Articulation agreements between public high schools and postsecondary institutions: Development, implementation, and results ( $\mathrm{PhD}$ dissertation), The Pennsylvania State University: Pennsylvania.

Comisión Externa Formación Técnica (2009). Bases para una política de formación técnico profesional en Chile. Informe ejecutivo. Santiago: Ministerio de Educación.

Consejo Nacional de Política Económica y Social, CONPES (2010). Lineamientos de política para el fortalecimiento del Sistema de Formación de Capital Humano, SFCH. Documento 3674. Colombia: CONPES.

Consejo Asesor Presidencial (2006). Informe final del Consejo Asesor Presidencial para la Calidad de la Educación. Santiago: Presidencia de la República.

Curtis, D. (2009). Student transfer. At a Glance. Australia: National Centre of Vocational Education Research.

Dirección de Presupuestos, Dipres (2009). Evaluación en profundidad programa Chilecalifica. Ministerio de Educación, Ministerio de Economía y Ministerio del Trabajo y Previsión Social. Santiago: Santiago Consultores.

Dortch, C. (2012). Carl D. Perkins career and technical education act of 2006: implementation issues. Washington, D.C.: Congressional Research Service.

Farías, M. (2013). Effects of early career decisions on future opportunities: the case of vocational education in Chile (PhD Dissertation). Stanford University: California.

Gaete, M, y Morales, R. (2011). Articulación del sistema de educación superior en Chile: posibilidades, tensiones y desafíos. Revista Calidad en la Educación, 35 (2), 51-89.

Haas, A.R. (1999). Trends in articulation arrangements for technical and vocational education in the South East Asian region. Melbourne: Unesco-Unevoc Centre, RMIT University.

Kuczera, M., \& Field, S. (2013). A skills beyond school review of the United States. OECD Reviews of Vocational Education and Training. OECD Publishing. DOI: $10.1787 / 9789264202153$-en

McKinney F., Fields E., Kurth P., \& Kelly F. (1988). Factors influencing the success of secondary/postsecondary vocational-technical education articulation programs. Columbus: National Center for Research in Vocational Education. 
116 ARTICULACIÓN DE LA EDUCACIÓN TÉCNICO PROFESIONAL: UNA CONTRIBUCIÓN PARA SU COMPRENSIÓN Y CONSIDERACIÓN DESDE LA POLÍTICA PÚBLICA - M. Sevilla, M. Farías y M. Weintraub

Ministerio de Educación de Chile, Mineduc (2006). Estrategia Bicentenario. Más y mejores técnicos para Chile. Santiago: Ministerio de Educación.

Ministerio de Educación de Chile, Mineduc (2011). Educación Técnico Profesional en Chile: antecedentes y claves de diagnóstico. Centro de Estudios, Ministerio de Educación.

Misko, J. (2006). Vocational education and training in Australia, the United Kingdom and Germany. Australia: National Centre for Vocational Education Research.

Musset, P., \& S. Field (2013). A skills beyond School Review of England, OECD Reviews of Vocational Education and Training. OECD Publishing/OECD. DOI:10.1787/9789264203594-en

National Centre for Vocational Education Research, NCEVER (2002). Linkages between secondary and post-secondary vocational education and training in China and Australia. Australia: National Centre for Vocational Education Research.

Organization for Economic Co-operation and Development, OECD (2004). Revisión de políticas nacionales de educación, Chile. Paris: OECD.

Organization for Economic Co-operation and Development, OECD (2009). Learning for jobs. OECD reviews of vocational education and training. Chile: a first report. Paris: OECD.

Organization for Economic Co-operation and Development, OECD (2010). Learning for jobs: synthesis report of the OECD reviews of vocational education and training, Paris: OECD.

Organization for Economic Co-operation and Development OECD (2012). Post-secondary vocational education and training: pathways and partnerships, higher education in regional and city development. OECD Publishing. DOI: 10.1787/9789264097551-en

OECD/IBRD/The World Bank (2012). Evaluaciones de políticas nacionales de educación: la educación superior en Colombia, OECD Publishing. DOI: $10.1787 / 9789264180710$-es

PhillipsKPA (2006). National study to improve outcomes in credit transfer and articulation from vocational and technical education to higher education. Stage 1 Report. Australia: Department of Education, Science and Training.

Robertson-Smith, M. (1990). Articulation models for vocational education. Washington, DC: Office of Educational Research and Improvement.

Sepúlveda, L. (2011). La enseñanza técnico profesional en Chile: orientaciones actuales desde la perspectiva de sus actores. En Evidencias para políticas 
públicas en educación: selección de Investigaciones Tercer Concurso FONIDE. Santiago: Centro de Estudios, Ministerio de Educación.

Shaw, C. (2012). The influence and outcomes of high school to college transition policy (Tech Prep) for career and technical education students in Massachusetts (PhD Dissertation). Boston: Northeastern University.

Stake, R. (1999). Investigación con estudio de casos. Madrid: Ediciones Morara.

Stipanovic, N., Lewis, M. V., \& Stringfield, S. (2012). Situating programs of study within current and historical career and technical educational reform efforts. International Journal of Educational Reform, 21(2), 80-97.

Unesco (2012). Consenso de Shanghai. Recomendaciones del Tercer congreso internacional sobre educación y formación técnica y profesional "Transformar la EFTP: forjar competencias para el trabajo y la vida". Shanghái: Unesco.

U.S Department of Education (2012). Aligning secondary and postsecondary education: experiences from career and technical education. Washington D.C.: Community College Virtual Symposium.

Watts, A. G. (2013). Career guidance and orientation. In Unesco-Unevoc (ed.). Revisiting global trends in TVET: reflections on theory and practice (pp.239-274). Bonn: Unesco-Unevoc.

Recibido: 07/10/2014

Aceptado: 27/11/2014 